\title{
PROCESOS DE DIVERSIFICACIÓN, INTENSIFICACIÓN Y DOMESTICACIÓN DURANTE EL HOLOCENO EN LAS TIERRAS ALTAS DEL NORTE DE ARGENTINA Y CHILE: APORTES DESDE LA PUNA DE SALTA
}

\section{PROCESSES OF DIVERSIFICATION, INTENSIFICATION AND DOMESTICATION DURING THE HOLOCENE IN THE HIGHLANDS NORTH OF ARGENTINA AND CHILE: CONTRIBUTIONS FROM THE PUNA OF SALTA}

\author{
Gabriel E. J. López ${ }^{1}$ y Federico Restifo ${ }^{2}$ \\ 1. CONICET-Instituto de Arqueología, Universidad de Buenos Aires. 25 de Mayo 217, 1002 Ciudad Autónoma \\ de Buenos Aires, Argentina. E-mail: gabelope@yahoo.com, \\ 2. CONICET-Instituto de Arqueología, Universidad de Buenos Aires. 25 de Mayo 217, 1002 Ciudad Autónoma \\ de Buenos Aires, Argentina. E-mail: federicorestifo@gmail.com
}

Presentado el: 13/04/2014 - Aceptado el: 17/09/2014

\begin{abstract}
Resumen
Este artículo analiza y discute los procesos de intensificación, domesticación y diversificación en el uso de los camélidos ocurridos entre ca 10000 y 3500 años AP en la Puna de Salta, comparando con distintas áreas de las tierras altas del Noroeste argentino y el Norte de Chile. La información arqueofaunística y lítica macroregional disponible se integra para el estudio de estos procesos. Los resultados indican cambios en el Holoceno medio y, fundamentalmente, en el Holoceno medio final. La evidencia faunística registra la presencia de camélidos domesticados y el aumento en la representación de camélidos subadultos, mientras que la tecnología lítica se caracteriza por la presencia de una mayor variedad de puntas de proyectil y la proliferación de formas base de hojas.
\end{abstract}

Palabras claves: Tierras altas del Norte de Argentina y Chile, Intensificación, Domesticación, Diversificación, Arqueofauna, Tecnología lítica 


\begin{abstract}
Intensification, domestication and diversification processes on the use of the camelids in the Puna of Salta (ca $10000-3500$ BP) are comparatively analyzed and discussed in this article considering different areas from the highlands of the Northwest of Argentina and North of Chile. Thus, archaeofaunal and lithic information is integrated to the study of these processes. Results highlight the occurrence of changes during the Middle Holocene and especially in the end of the Middle Holocene. The archaeofaunal evidence exhibits the presence of domesticated camelids and an increase in subadult camelid frequency throughout the Holocene. In relation to lithic assemblages, an increment in projectile point classes and the proliferation of blade technology are recorded.
\end{abstract}

Keywords: Highlands of North of Argentina and Chile, Intensification, Domestication, Diversification, Archaeofauna, Lithic technology

\title{
Introducción
}

Distintas investigaciones arqueológicas en las tierras altas del Noroeste argentino y el Norte de Chile, han dado cuenta de procesos de cambio en el uso de los camélidos durante el Holoceno (Cartajena 2013; Mengoni Goñalons y Yacobaccio 2006; Mondini et al. 2013; Olivera 2012; Yacobaccio 2001). Particularmente, se destacó la intensificación en el consumo de estos recursos y su posterior domesticación (Olivera 2012; Yacobaccio 2006). Estos procesos se habrían iniciado en el Holoceno medio (ca. 7000-6000 AP), y se habrían consolidado en el Holoceno medio final (ca. 5000-4000 AP). En la Puna de Salta, Noroeste argentino, los procesos de intensificación y domesticación han comenzado a estudiarse más recientemente (ver López y Restifo 2012).

En términos amplios, la intensificación puede ser definida como la búsqueda de un aumento de la productividad por unidad de espacio o recurso (Broughton 1999, Johnson et al. 2009; Neme 2002, Yacobaccio 2006). Por su parte, la domesticación implica un proceso de adaptación de una población de animales y/o plantas a los humanos y al ambiente por cambios genéticos que ocurren en varias generaciones y eventos de desarrollo ambientalmente inducidos (Yacobaccio y Vilá 2002). En este sentido, los cambios en la base de recursos pueden implicar: 1) la inclusión de nuevos taxones antes no consumidos por su bajo rendimiento, 2) la intensificación en el consumo de aquellos de alto ranking, y 3) la domesticación. Este trabajo desarrolla y discute las dos últimas opciones.

En las tierras altas andinas, los camélidos constituyen los recursos de más alto ranking. Estos taxones incluyen especies silvestres y domesticadas. Las primeras están representadas por el guanaco (Lama guanicoe) y la vicuña (Vicugna vicugna), mientras que las segundas por la llama (Lama glama) y la alpaca (Lama pacos), esta última ausente en el Noroeste argentino.

En relación con la intensificación en el consumo de camélidos silvestres, Yacobaccio (2001) plantea que existe un aumento sostenido de la representación de estos taxones en contextos arqueológicos a partir del Holoceno medio. Esta situación lleva a discutir si es posible intensificar la explotación de estos recursos silvestres sin reducir la eficiencia, al contrario de lo ocurrido en otros casos (e.g. Broughton 1999). Para evaluar este aspecto es importante analizar el rol de la tecnología en el aumento de la productividad y la tasa de retorno. En contextos de intensificación se esperan innovaciones tecnológicas, incluyendo alternativas más costosas pero eficientes (Fitzhugh 2001; Quintero y Wilke 1995). 
Otra de las alternativas para incluir nuevos recursos ha sido la domesticación de camélidos. La inclusión de animales domesticados amplía los taxones disponibles, y en consecuencia, diversifica el nicho económico. En este sentido, Winterhalder et al. (1999) postulan que las estrategias diversificadoras son necesarias para minimizar el riesgo. Más concretamente, tienden a evitar la caída por debajo de un umbral adaptativo.

Desde una perspectiva ecológica evolutiva, este trabajo analiza y discute los procesos de intensificación, domesticación y diversificación en el uso de los camélidos entre ca 10000 y 3500 años AP en la Puna de Salta. Asimismo, se compara el material arqueofaunístico y lítico de esta región con el de distintas áreas de las tierras altas del Noroeste argentino y el Norte de Chile, con el objetivo de explorar estos procesos en la escala macroregional.

\section{Áreas de estudio y marco ambiental}

Las investigaciones en la Puna de Salta se han focalizado en distintas áreas. En Pastos Grandes, ubicada a más de 4000 msnm, se destaca el sitio Alero Cuevas (Figura 1), con una secuencia que abarca todo el Holoceno y por ello constituye una base de referencia para el estudio regional (López 2008; López y Restifo 2012). Asimismo, se incluyen muestras provenientes de áreas cercanas a Pastos Grandes, como el Valle de San Antonio de los Cobres, y más específicamente la evidencia del sitio a cielo abierto Ramadas Perfil Norte (Figura 1), fechada hacia fines del Holoceno medio (Muscio et al 2011; Restifo 2013a). También se considera la información arqueológica del salar de Pocitos, que presenta evidencia en capa desde el Holoceno medio en el sitio Abrigo Pozo Cavado (Figura 1, López et al. 2013).

La información arqueológica de la Puna de Salta se compara con distintas áreas de la Puna argentina y el norte de Chile. Los contextos de la Puna argentina analizados corresponden a los sectores occidental y oriental de Jujuy, y a la cuenca de Antofagasta de la Sierra, en Catamarca (ver Figura 1). En el caso del norte de Chile, este estudio se focaliza en la cuenca del salar de Atacama (ver Figura 1).

Las tierras altas de los Andes centro sur presentan rasgos ambientales comunes tales como la aridez general, la heterogeneidad de ambientes locales o parches de recursos, la baja productividad primaria, la impredictibilidad en la caída de precipitaciones, y la estacionalidad marcada (Muscio y López 2011; Yacobaccio et al. 1997/1998). Asimismo, a lo largo del Holoceno, se han planteado cambios ambientales (Morales 2011).

El Holoceno temprano (ca. 10000 - 8000 AP) se caracterizó por una mayor humedad que en la actualidad, lo que habría generado un ambiente menos segmentado en "parches". El poblamiento inicial de la región se habría dado en este contexto ambiental más favorable, potencialmente con una alta disponibilidad de recursos de caza como los camélidos. Las expectativas en relación con las ocupaciones humanas que se desprenden de este modelo paleoambiental general para el Holoceno temprano son una mayor movilidad residencial, tamaños de grupos pequeños, menor densidad poblacional, y en consecuencia, una baja circunscripción espacial (Yacobaccio y Vilá 2002).

A nivel general, el Holoceno medio (ca. 8000 - 4000/3500 AP) se caracterizó por un incremento de la aridez, exhibiendo una alta variabilidad local. Este cambio habría llevado a una alta segmentación espacial en "parches" de recursos. Esto habría impactado en los patrones de movilidad humana dando lugar a una concentración de las poblaciones 
en aquellos sectores con disponibilidad de recursos claves para la subsistencia, y en consecuencia, una distribución sumamente heterogénea de los grupos en el espacio. A partir de estas características, se espera una menor movilidad residencial, tamaños de grupo más grandes, una alta circunscripción espacial, mayor competencia por los recursos y un incremento de la demanda energética (Yacobaccio y Vilá 2002). Hacia el Holoceno medio final ( $c a .5000$ - 4000 AP), estos procesos se habrían acentuado (Aschero 1994; López 2008).

Por último, durante el Holoceno tardío (ca. 4000/3500 AP en adelante), se habrían instalado las condiciones climáticas actuales, algo más húmedas en relación con el Holoceno medio, pero con una continuidad de las características de aridez y segmentación espacial. En estos contextos, generalmente se ha propuesto una mayor estabilidad residencial, una reorganización de los grupos en torno a un nicho económico basado en la producción de alimentos y demografía creciente (Olivera 2012; Yacobaccio y Vilá 2002).

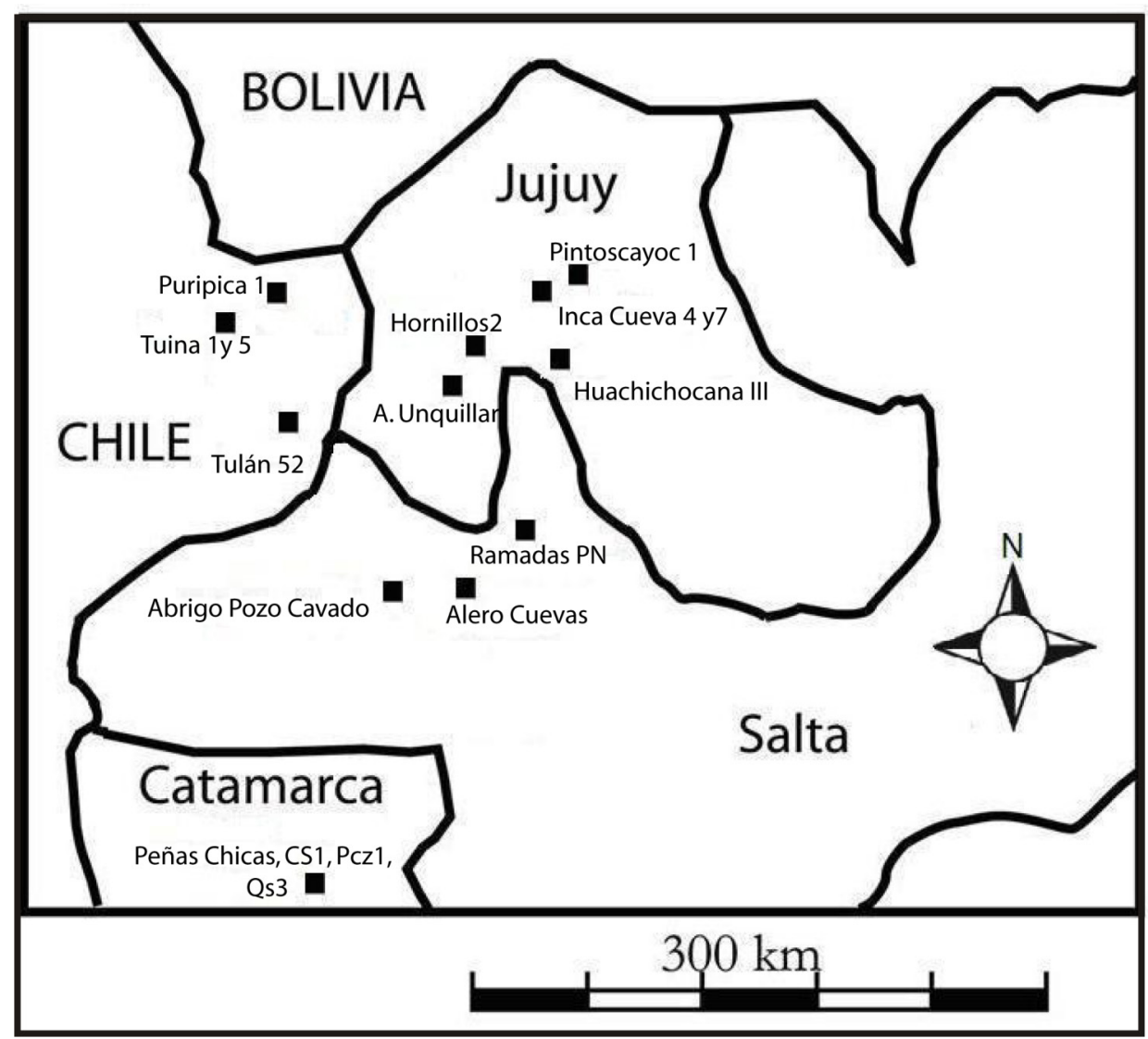

Figura 1. Mapa con la localización de los sitios arqueológicos mencionados en el texto. 


\section{Metodología}

El estudio de los procesos de cambio ocurridos a lo largo del Holoceno en la Puna de Salta y más generalmente en distintos sitios de las tierras altas del Noroeste argentino y el Norte de Chile, se centró en el análisis de dos líneas de evidencia: la arqueofauna y el material lítico. Como marco temporal para estudiar al cambio en escalas de largo plazo se decidió utilizar la distinción entre Holoceno temprano, medio y medio final (López 2008, Yacobaccio 2013).

El análisis arqueofaunístico se focalizó en el estudio de los camélidos, considerando como indicadores el NISP \%, la diferenciación interespecífica, y la representación de especímenes no fusionados. El NISP \% hace referencia al porcentaje del número de especímenes identificados por taxón. Dentro de cada bloque temporal se determinó el promedio de los valores de NISP $\%$ procedente de distintos sitios.

Por su parte, la diferenciación interespecífica de camélidos se basó en el registro bibliográfico de la presencia/ausencia de las distintas especies desde el Holoceno temprano hasta el Holoceno medio final, a partir de indicadores osteométricos (Aschero et al. 2012; Cartajena 2013; Elkin 1996; López 2008, 2013; Núñez et al. 2005; Yacobaccio 2013). A los fines de análisis de este trabajo, se considera suficiente el análisis cualitativo (presencia/ausencia de especies de camélidos). Esto debido a que los estudios cuantitativos osteométricos realizados macroregionalmente no responden a los mismos parámetros de análisis, utilizándose distintas medidas y elementos óseos, que no favorecen la comparación.

En relación con la representación de especímenes no fusionados, se contabilizó el porcentaje comparado para dar cuenta de la variabilidad a lo largo del Holoceno. Por medio de este indicador, se puede realizar una aproximación al perfil etario de los camélidos consumidos a lo largo del tiempo, exhibiendo cambios relacionados con procesos de intensificación y/o domesticación (Mengoni Goñalons y Yacobaccio 2006; Wheeler 1998). Al igual que en el caso del NISP \%, con la representación de especímenes no fusionados se utilizó el promedio de los valores procedentes de distintos sitios para el Holoceno temprano, medio y medio final. A su vez, se consideró el coeficiente de variación para analizar si los resultados en la variabilidad entre sitios influyen en la variación del promedio para cada contexto cronológico.

En relación con la tecnología lítica, los indicadores analizados fueron: la diversidad de clases de puntas de proyectil, por un lado, y la representación diferencial de formas base de instrumentos, por otro. Asimismo, para ambos indicadores se consideró una escala macroregional y su variación a lo largo del Holoceno.

Para el estudio de la diversidad de clases de puntas de proyectil, se compararon distintas morfologías definidas a nivel macroregional en la bibliografía de la Puna argentina y el norte de Chile, basadas en términos generales en variantes de limbo y pedúnculo (Aschero 1984; Aschero et al. 2011; De Souza 2004; Fernández 1983; Hocsman 2006; Hoguin y Yacobaccio 2012; López 2013; Martínez 2003; Moreno 2011; Núñez et al. 2005; Patané Aráoz 2013; Pintar 2014; Ratto 2003; Restifo 2013a, 2013b; entre otros). A partir de la diversidad de clases, se calculó la riqueza (número de clases) por unidad de análisis (Holoceno temprano, medio y medio final). Si bien se reconoce que estas clases no captan la variabilidad total de puntas, se plantea aquí que permiten comparar algunos patrones generales de forma y tamaño de 
las mismas. De esta manera, se puede generar una comparación regional ilustrativa de la variabilidad de puntas, incluyendo aquellas presentes tanto en capa como en superficie. Es importante destacar que no se consideraron algunos ejemplares provenientes de colecciones, como el caso de la punta "cola de pescado" detectada por Patané Aráoz (2013), que correspondería a la transición Pleistoceno - Holoceno. También se aclara que a los fines de este trabajo se analizan clases a partir de su riqueza y su presencia/ausencia, independientemente de sus frecuencias.

El estudio de las formas base consideró el aumento o disminución en la representación de la tecnología de lascas y hojas entre regiones y a lo largo del Holoceno (Aschero 1975; Bar Yosef y Kuhn 1999; López 2008; Restifo 2013b). Esta distinción general entre lascas y hojas permite diferenciar dos técnicas de extracción de forma base que implican costos distintos en términos de secuencia de talla, aprendizaje y destreza técnica (Boëda 1997; Nelson 1991). La extracción de hojas demanda la preparación de núcleos, implicando la generación de una arista específica para la primera extracción y un margen de error más estrecho, ya que una falla en la preparación de plataformas o aristas puede impedir la continuidad en el uso del núcleo.

Se destaca que la variación en la representación de la forma base no se abordó mediante un análisis cuantitativo, dado que en la bibliografía disponible no hay un criterio unificado en la presentación de los datos, lo que no favorece la comparación. Por este motivo, se consideraron las tendencias generales mencionadas en la bibliografía hacia el aumento o la disminución de distintas formas base entre el Holoceno temprano, medio y medio final (Aschero y Hocsman 2011; Fernández 1983; Fernández Distel 2007; Hoguin 2013; Muscio et al 2011; Núñez et al. 2005; Restifo y Hoguin 2012), sin evaluar frecuencias.

Los resultados se estructuraron en dos partes: la primera presenta la evidencia arqueológica de la Puna de Salta (principalmente aquella procedente de los sitios Alero Cuevas, Ramadas Perfil Norte y Abrigo Pozo Cavado) y, la segunda, a la comparación macroregional entre este registro y el de otras áreas de las tierras altas del Noroeste argentino y el Norte de Chile.

\section{Resultados}

Puna de Salta

\section{Arqueofaunas}

En la Puna de Salta, el NISP \% muestra escasa variación a lo largo del Holoceno, ya que los camélidos siempre superan el 90 \% (Figura 2). La muestra considerada proviene de los sitios Alero Cuevas en Pastos Grandes, y Abrigo Pozo Cavado en Pocitos.

En cambio, en estos sitios se observó una alta variación en el tamaño de los especímenes óseos de camélidos, que representarían especies distintas. Los especímenes medidos para todas las capas correspondieron principalmente a falanges primeras $(\mathrm{N}=42)$, indicando la representación de tamaños tanto de camélidos silvestres (guanaco y vicuña) como posiblemente llamas (López 2013). La presencia de elementos que corresponderían a llamas (o tamaños similares) se registró en las capas fechadas entre 5000 y 3900 años AP, es decir, en el Holoceno medio final (López 2013; ver Tabla 1). 
La representación de especímenes no fusionados es variable a lo largo del Holoceno. Se destacan los cambios registrados hacia fines del Holoceno medio en la estratigrafía de los sitios Abrigo Pozo Cavado y Alero Cuevas. Es notable el aumento de especímenes no fusionados con respecto a lo registrado en contextos cronológicos anteriores (Figura 3).

\section{Lítico}

La riqueza de clases de puntas de proyectil es mayor a partir del Holoceno medio (Figura 4). Este incremento es notable, ya que se destacan siete nuevas variantes no identificadas en contextos del Holoceno temprano. En el Holoceno medio final se registran cinco nuevas variantes. Al considerar el Holoceno medio como un bloque (sin dividir en Holoceno medio final), se observan 12 nuevas clases.

$\mathrm{Al}$ analizar el material lítico en conjunto, y específicamente las formas base, se destaca la mayor presencia de tecnología de hojas o extracciones laminares en el Holoceno medio final, que en el sitio Alero Cuevas alcanza alrededor de un 40 \% (López y Restifo 2012; ver Tabla 3). Esta tecnología se hace presente como forma base de una clase particular de artefactos a los que se denominó "lanceolados unifaciales" (López 2008) o "saladillenses" (Fernández 1983; Fernández Distel 1978). Dicha clase de artefactos se registró en asociación con un núcleo de hojas en el sitio Alero Cuevas en Pastos Grandes en la capa de ca. 5100- 4200 AP, y no se encuentra presente en las capas del Holoceno temprano y del Holoceno tardío (López y Restifo 2012). En consecuencia, esta clase de artefactos se circunscribe a fines del Holoceno medio, tendencia también observada en el sitio Ramadas Perfil Norte, en San Antonio de los Cobres, con ocupaciones fechadas en ca 5200 AP (Muscio et al. 2011).

\section{Comparación macroregional}

Arqueofauna

Los datos tomados de Yacobaccio (2013), indican que los camélidos aumentan notablemente en NISP \% a partir del Holoceno medio sobre un total de 10 sitios de la Puna argentina (Figura 2). Esto mismo se evidencia en el Norte de Chile sobre un total de 12 sitios (Figura 2).

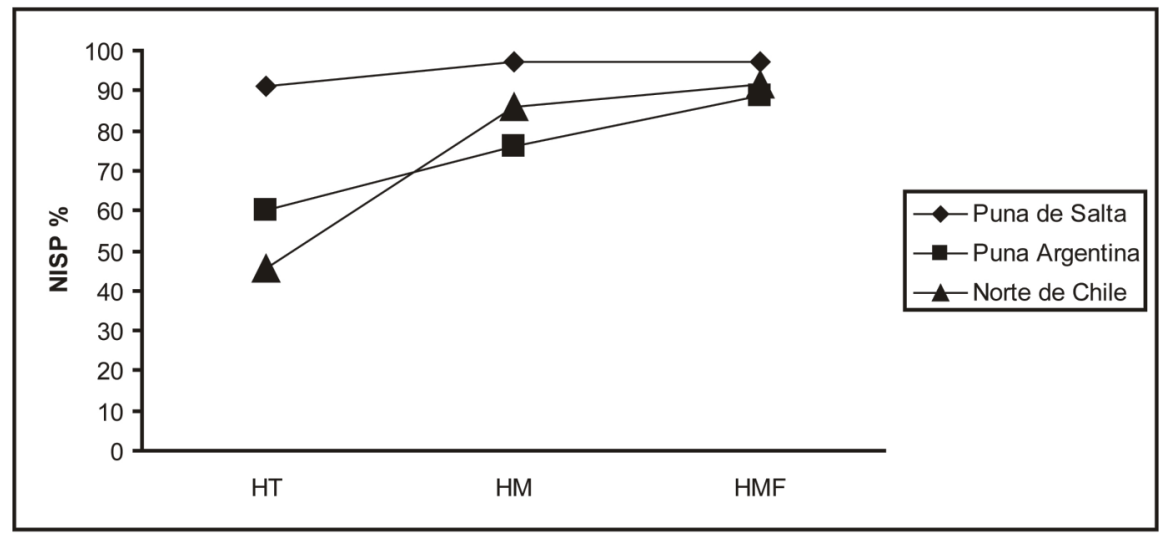

Figura 2: NISP \% de camélidos comparativo entre el Holoceno temprano (HT), el Holoceno medio (HM) y el Holoceno medio final (HMF) en la Puna argentina en general, norte de Chile y la Puna de Salta en particular. 


\begin{tabular}{|c|c|c|c|c|}
\hline & Puna de Salta & $\begin{array}{l}\text { Puna de } \\
\text { Catamarca }\end{array}$ & Puna de Jujuy & $\begin{array}{l}\text { Cuenca del } \\
\text { salar de } \\
\text { Atacama }\end{array}$ \\
\hline $\begin{array}{l}\text { Holoceno } \\
\text { temprano }\end{array}$ & $\begin{array}{l}\text { - Guanaco de } \\
\text { tamaño más } \\
\text { grande que el } \\
\text { actual } \\
\text { - Vicuña } \\
\text { - Procedencia: } \\
\text { Alero Cuevas }\end{array}$ & $\begin{array}{l}\text { - Guanaco de } \\
\text { tamaño más } \\
\text { grande que el } \\
\text { actual } \\
\text { - Vicuña } \\
\text { - Procedencia: } \\
\text { Quebrada Seca } \\
3\end{array}$ & $\begin{array}{l}\text { - Guanaco más } \\
\text { grande que el } \\
\text { actual } \\
\text { - Vicuña } \\
\text {-Procedencia: } \\
\text { Hornillos 2, Inca } \\
\text { Cueva 4, } \\
\text { Huachichocana } \\
\text { III }\end{array}$ & $\begin{array}{l}\text { - Guanaco más } \\
\text { grande que el } \\
\text { actual } \\
\text { - Vicuña } \\
\text { Procedencia: } \\
\text { Tuina } 5\end{array}$ \\
\hline $\begin{array}{l}\text { Holoceno } \\
\text { medio }\end{array}$ & $\begin{array}{l}\text { - Guanaco } \\
\text { - Vicuña } \\
\\
\text { Procedencia: } \\
\text { Alero Cuevas, } \\
\text { Abrigo Pozo } \\
\text { Cavado }\end{array}$ & $\begin{array}{l}\text { - Guanaco } \\
\text { - Vicuña } \\
\text { Procedencia: } \\
\text { Quebrada Seca } \\
3\end{array}$ & $\begin{array}{l}\text { - Guanaco } \\
\text { - Vicuña } \\
\text { - Tamaño } \\
\text { similar a llama } \\
\text { Procedencia: } \\
\text { Hornillos } 2\end{array}$ & $\begin{array}{l}\text { - Guanaco } \\
\text { - Vicuña } \\
\\
\text { Procedencia: } \\
\text { Puripica } 3\end{array}$ \\
\hline $\begin{array}{l}\text { Holoceno } \\
\text { medio final }\end{array}$ & $\begin{array}{l}\text { - Guanaco } \\
\text { - Vicuña } \\
\text { - Tamaño } \\
\text { similar a llama } \\
\\
\text { Procedencia: } \\
\text { Abrigo Pozo } \\
\text { Cavado, Alero } \\
\text { Cuevas }\end{array}$ & \begin{tabular}{|l} 
- Guanaco \\
- Vicuña \\
- Tamaño \\
similar a llama \\
\\
Procedencia: \\
Quebrada Seca \\
3 (sin tamaño \\
de llama) y \\
Peñas Chicas \\
1.5 (con \\
tamaño de \\
llama)
\end{tabular} & $\begin{array}{l}\text { - Tamaño } \\
\text { similar a llama } \\
\\
\text { Procedencia: } \\
\text { Huachichocana } \\
\text { III, Inca Cueva } \\
\text { 7, Alero } \\
\text { Unquillar }\end{array}$ & $\begin{array}{l}\text { - Guanaco } \\
\text { - Vicuña } \\
\text { - Tamaño } \\
\text { similar a llama } \\
\\
\text { Procedencia: } \\
\text { Puripica 1, } \\
\text { Tulán } 52\end{array}$ \\
\hline Referencia & $\begin{array}{l}\text { López (2008, } \\
\text { 2013) }\end{array}$ & $\begin{array}{l}\text { Aschero et al } \\
\text { (2012), Elkin } \\
\text { (1996). }\end{array}$ & $\begin{array}{l}\text { Yacobaccio } \\
(2013)\end{array}$ & $\begin{array}{l}\text { Cartajena } \\
\text { (2013), Núñez } \\
\text { et al (2005) }\end{array}$ \\
\hline
\end{tabular}

Tabla 1. Identificación de especies de camélidos a partir de osteometría en el Holoceno temprano, medio y medio final en la Puna de Salta, Jujuy y Catamarca, y la cuenca del salar de Atacama (Chile). 
La diferenciación interespecífica de camélidos, principalmente a partir de indicadores osteométricos, muestra la presencia de guanacos -con tamaños más grandes que en la actualidad- y vicuñas, durante el Holoceno temprano. En el Holoceno medio, el tamaño de los guanacos se reduce y los mismos se encuentran presentes en todas las áreas, al igual que las vicuñas. En Susques, Puna de Jujuy, el sitio Hornillos 2 (Yacobaccio 2013) presenta individuos de un tamaño grande que podrían estar indicando la ocurrencia de cambios relacionados con la domesticación. En el Holoceno medio final, los cambios en la osteometría se generalizan en todas las áreas, con la aparición de camélidos de tamaños grandes similares a la llama actual (Tabla 1).

Los resultados obtenidos por Yacobaccio (2013:29) en relación con la representación de especímenes no fusionados para el conjunto de los sitios de la Puna argentina/Norte de Chile ( $\mathrm{N}=16$, algunos multicomponentes), muestran una variación importante entre el Holoceno temprano, medio y medio final (Figura 3). Es interesante la caída registrada en la frecuencia relativa de los especímenes no fusionados en el Holoceno medio y su aumento notable en el Holoceno medio final (se incluyen en este análisis los sitios de la Puna de Salta). En este sentido, el coeficiente de variación entre sitios para cada contexto cronológico presenta una tendencia moderada a alta. Los resultados muestran que la menor variación entre sitios se da en el Holoceno medio final con un CV de $37 \%$, por lo que no sería determinante en el aumento de especímenes no fusionados registrado. Por el contrario, el CV es $48 \%$ y $65 \%$ en el Holoceno temprano y medio, respectivamente.

De todas maneras, no puede soslayarse que el promedio de los valores de especímenes no fusionados de Alero Cuevas y Abrigo Pozo Cavado es más alto en el Holoceno medio final que el promedio disponible para la Puna argentina y el Norte de Chile. Sin embargo, el patrón general a nivel comparativo entre el conjunto de los sitios en la Puna argentina/ Chile y la Puna de Salta presenta trayectorias de cambio bastante similares.

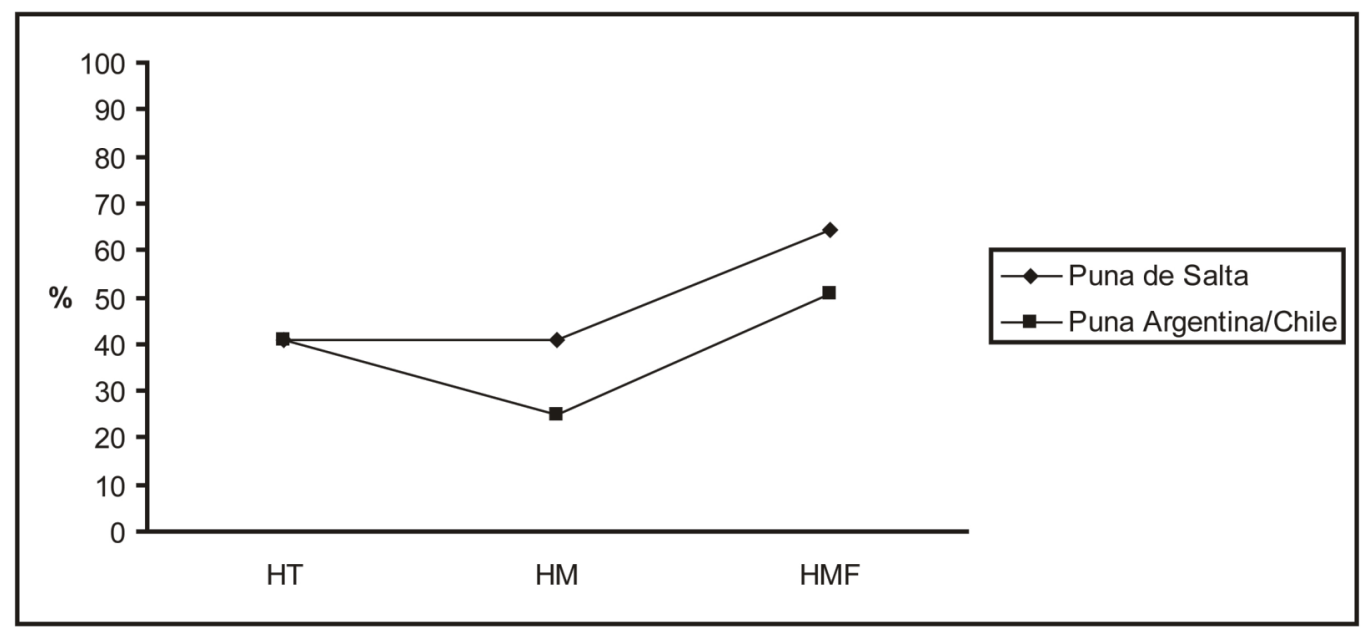

Figura 3: Porcentaje comparativo de especímenes no fusionados de camélidos del Holoceno temprano (HT), el Holoceno medio (HM) y el Holoceno medio final (HMF) en la Puna argentina/ Chile en general y la Puna de Salta en particular. 
Lítico

Los resultados que se observan en la tabla 2 y en la figura 4 permiten dar cuenta de un patrón complejo para la interpretación. En general las clases representadas se incrementan a partir del Holoceno medio en una proporción notable (el doble de las presentes en el Holoceno temprano). Al tomar todo el Holoceno medio como un bloque (sin diferenciar el Holoceno medio final), esta proporción aumenta, ya que se observan 11 nuevas clases. Comparativamente, en la Puna de Salta la riqueza total de clases pasa de 3 a 14 (se incluyen aquellas que persisten), mientras que considerando de modo conjunto a la Puna argentina la riqueza aumenta de 5 en el Holoceno temprano a 18 en el Holoceno medio, y de 5 a 11 en la cuenca de Atacama en el Norte de Chile. Cabe destacar que no hay una ruptura evidente entre las clases del Holoceno temprano y el Holoceno medio, dado que persisten algunas variantes morfológicas (Figura 4).

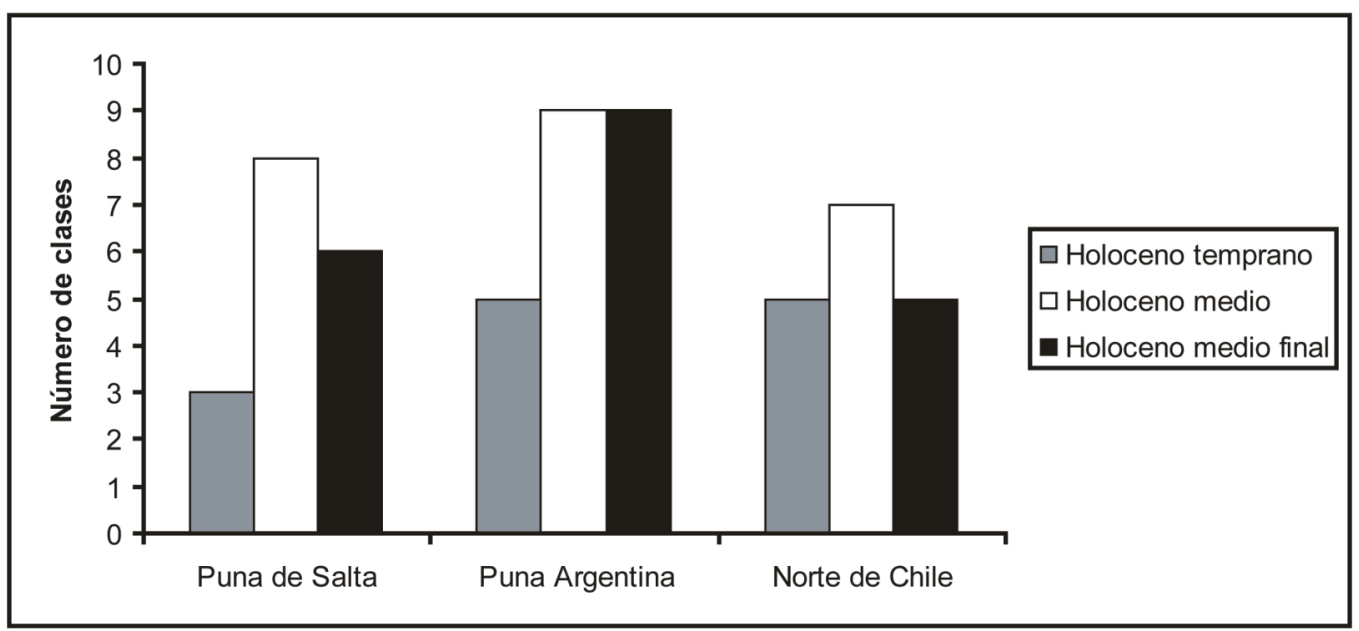

Figura 4. Riqueza comparativa de clases de puntas de proyectil en el Holoceno temprano, medio y medio final de la Puna de Salta en particular y de la Puna argentina y el Norte de Chile en general.

A nivel macroregional, se destaca la variabilidad y la recurrencia de clases por regiones. Para el Holoceno temprano, las puntas apedunculadas de limbo triangular y base recta (clase 1) aparecen en las distintas áreas, tanto en Argentina como en Chile, incluyendo también variantes de base cóncava. Otras clases de puntas son las de limbo triangular con pedúnculo destacado, bordes paralelos y base recta (clase 3), denominadas en Catamarca como Quebrada Seca B (Martínez 2003); puntas de limbo triangular alargado y base escotada (clase 2), definidas en el Norte de Chile como Huiculunche 2 (De Souza 2004); y puntas triangulares alargadas con pedúnculo y aletas, y morfología tetragonal (clase 5) conocidas como "San Martín" (Núnez et al. 2005; Hoguin y Yacobaccio 2012), características del Norte de Chile en el Holoceno temprano.

Durante el Holoceno medio continúan ciertas clases como Huiculunche 2 o las puntas triangulares apedunculadas, a las que se suman otras nuevas. Dentro de estas últimas se destacan las clases con limbo lanceolado y longitud aproximada de $10 \mathrm{~cm}$. También, tanto en la Puna de Salta como en la Puna de Catamarca, se observan clases de limbo lanceolado y base convexilínea (clase 10), conocidas bajo el nombre de tipo morfológico Peñas de la Cruz A (Martínez 2003); y de limbo lanceolado y base escotada (clase 9), definida en Catamarca como Quebrada Seca C (Martínez 2003, Pintar 2014). Asimismo, es destacable el caso de las 
puntas San Martín, cuya continuidad es registrada en el Norte de Chile, y que aparecen en la Puna Argentina para inicios del Holoceno medio, como se evidencia en el sitio Hornillos 2, en Jujuy (Hoguin y Yacobaccio 2012). En este sentido, es relevante destacar su presencia en la Puna de Salta, comunicada recientemente (Patané Aráoz 2013; Restifo 2014 observación personal). También se registra la presencia de una clase de limbo lanceolado con pedúnculo de base curvilínea y hombros (clase 11), similar al tipo Peñas Chicas B.a (Hocsman 2006).

En el bloque del Holoceno medio final llama la atención el patrón de diversificación en la Puna de Catamarca, cuyas clases pueden tener correlatos en otras áreas. En este caso se destaca la clase de limbo lanceolado y tamaño pequeño (clase 12), presente en todas las áreas, y observada en contextos del Norte de Chile desde inicios del Holoceno medio. Asimismo, se observa la aparición de una clase de limbo triangular con pedúnculo de bordes convergentes rectos y morfología general pentagonal (clase 14), con presencia en Catamarca (tipo morfológico Quebrada Seca F) y en la Puna de Salta y Jujuy (Fernández 1983; Hocsman 2006; Restifo 2013a, 2013b). Otras clases de puntas son de limbo lanceolado pero de menor tamaño que Peñas de la Cruz A (clase 5); de limbo triangular, hombros y pedúnculo de base curvilínea (clase 13); y una clase específica en la Puna de Catamarca de limbo lanceolado y pedúnculo (clase 17). Las puntas en mandorla (clase 16), se registran de manera notoria en el sitio Inca Cueva 7, Jujuy (Aschero et al. 2011), y han sido recientemente observadas en la Puna de Salta (López 2013).

\begin{tabular}{|c|c|c|c|c|}
\hline & Puna de Salta & Puna de Catamarca & Puna de Jujuy & Cuenca del S. de Atacama \\
\hline H. Temprano & & & & \\
\hline H. Medio & $\Lambda$ & & & \\
\hline H. Medio fina & & & & \\
\hline Referencias & López (2013), Patané Aráoz (2013), Restifo (2013) & Martínez (2003), Aschero y Hocsman (2011), Pintar (2014) & $\begin{array}{l}\text { Fernández Distel (1974), Aschero } \\
\text { (1984), Aschero et a1. (2011), } \\
\text { Hoguin y Yacobaccio (2012), } \\
\text { Lavalle et al } 1997\end{array}$ & De Souza (2004), Núñez et al. (2005) \\
\hline
\end{tabular}

Tabla 2. Comparación de clases de puntas de proyectil entre el Holoceno temprano, medio y medio final en la Puna de Salta, Catamarca y Jujuy, y la cuenca del salar de Atacama (Chile). 1: Punta apedunculada de limbo triangular pequeña, 2: Punta de limbo triangular o lanceolado alargado y base escotada, 3: Punta de limbo triangular o lanceolado con pedúnculo destacado de bordes rectos, 4: Punta apedunculada de limbo lanceolado y tamaño mediano, 5: Punta de limbo triangular alargado, pedúnculo destacado de bordes convergentes y aletas (morfología tetragonal), 6: Punta de limbo triangular con escotadura en la base (forma acorazonada), 7: Punta apedunculada de limbo triangular alargado y tamaño mediano, 8: Punta de limbo triangular pequeña con pedúnculo y aletas, 9: Punta de limbo lanceolado, con presencia de denticulado, bordes paralelos rectos, base escotada y tamaño grande, 10: Punta apedunculada de limbo lanceolado, base convexilínea y tamaño grande, 11: Punta de limbo lanceolado, pedúnculo de base convexilínea y hombros, tamaño mediano, 12: Punta apedunculada de limbo lanceolado y tamaño pequeño, 13: Punta de limbo triangular, pedúnculo destacado de bordes convergentes y hombros, tamaño pequeño, 14: Punta de limbo triangular, pedúnculo destacado o esbozado de bordes convergentes, tamaño mediano (morfología pentagonal), 15: Punta de limbo triangular y bordes rectos, pedúnculo destacado o esbozado, base convexilínea y tamaño pequeño, 16: Punta de limbo lanceolado, con presencia de una punta en cada extremo, tamaño pequeño (tipo mandorla), 17: Punta de limbo triangular o lanceolado, pedúnculo destacado, tamaño pequeño, 18: Punta de limbo lanceolado, pedúnculo destacado de base convexilínea y tamaño mediano. 


\begin{tabular}{|c|c|c|c|c|}
\hline & Puna de Salta & $\begin{array}{l}\text { Puna de } \\
\text { Catamarca }\end{array}$ & Puna de Jujuy & $\begin{array}{l}\text { Cuenca del S. } \\
\text { de Atacama }\end{array}$ \\
\hline H. Temprano & $\begin{array}{l}\begin{array}{l}\text { Ausencia de } \\
\text { tecnologia de } \\
\text { hojas, } \\
\text { predominio de } \\
\text { lascas }\end{array} \\
\text { Presencia de } \\
\text { ejemplares } \\
\text { aislados con } \\
\text { forma base de } \\
\text { módulo } \\
\text { laminar }\end{array}$ & $\begin{array}{l}\text { Ausencia de } \\
\text { tecnología de } \\
\text { hojas } \\
\text { Predominio de } \\
\text { lascas }\end{array}$ & $\begin{array}{l}\text { Indicios de } \\
\text { tecnologia de } \\
\text { hojas (escasos } \\
\text { ejemplares), } \\
\text { predominio de } \\
\text { tecnologia de } \\
\text { lascas. }\end{array}$ & $\begin{array}{l}\text { Predominio de } \\
\text { tecnología de } \\
\text { lascas }\end{array}$ \\
\hline H. Medio & $\begin{array}{l}\text { Predominio de } \\
\text { lascas } \\
\text { Aparición de } \\
\text { especímenes } \\
\text { de hojas, } \\
\text { aunque no es } \\
\text { posible } \\
\text { referirse a un } \\
\text { sistema } \\
\text { tecnológico. }\end{array}$ & $\begin{array}{l}\text { Ausencia de } \\
\text { tecnologia de } \\
\text { hojas, } \\
\text { predominio de } \\
\text { lascas }\end{array}$ & $\begin{array}{l}\text { Indicios de } \\
\text { tecnología de } \\
\text { hojas (escasos } \\
\text { ejemplares). } \\
\text { Predominio de } \\
\text { tecnología de } \\
\text { lascas }\end{array}$ & $\begin{array}{l}\text { Predominio de } \\
\text { tecnología de } \\
\text { lascas }\end{array}$ \\
\hline H. Medio final & $\begin{array}{l}\text { Proliferación } \\
\text { de la } \\
\text { tecnología de } \\
\text { hojas hacia ca. } \\
5000 \text { AP. } \\
\text { Aumento de } \\
\text { instrumentos } \\
\text { sobre hojas } \\
\text { (lanceolados } \\
\text { unifaciales), y } \\
\text { proporciones } \\
\text { similares en } \\
\text { relación a las } \\
\text { lascas. } \\
\text { Presencia de } \\
\text { núcleos } \\
\text { orientados a la } \\
\text { obtención de } \\
\text { hojas, y de } \\
\text { desechos de } \\
\text { talla } \\
\text { vinculados con } \\
\text { el mismo tipo } \\
\text { de tecnología. } \\
\text { Asociación en } \\
\text { capa en el sitio } \\
\text { Alero Cuevas } \\
\text { (capa de } 5100 \text { - } \\
\text { 4200 AP)y yen } \\
\text { el sitio } \\
\text { Ramadas Perfil } \\
\text { Norte (5200 } \\
\text { AP). }\end{array}$ & $\begin{array}{l}\text { Ausencia de } \\
\text { tecnologia de } \\
\text { hojas, } \\
\text { predominio de } \\
\text { lascas }\end{array}$ & $\begin{array}{l}\begin{array}{l}\text { Proliferación } \\
\text { de tecnología } \\
\text { de hojas hacia } \\
\text { ca. } 5000 \mathrm{AP}\end{array} \\
\text { Aumento de } \\
\text { instrumentos } \\
\text { formatizados } \\
\text { sobre hojas } \\
\text { (lanceolados } \\
\text { unifaciales o } \\
\text { Saladillo), en } \\
\text { sitios del ărea } \\
\text { de Salinas } \\
\text { Grandes, } \\
\text { Susques } \\
\text { (superficie)y } \\
\text { El Aguilar } \\
\text { (superficie). }\end{array}$ & $\begin{array}{l}\text { Proliferación } \\
\text { de la } \\
\text { tecnología de } \\
\text { hojas, altas } \\
\text { proporciones } \\
\text { de láminas en } \\
\text { sitios de las } \\
\text { Quebradas de } \\
\text { Puripicay } \\
\text { Tulán, entre ca. } \\
5000 \text { y } 4000 \\
\text { AP. }\end{array}$ \\
\hline Referencias & $\begin{array}{l}\text { López (2008), } \\
\text { Muscio et al } \\
\text { (2011), Restifo } \\
\text { y Hoguin } \\
\text { (2012) }\end{array}$ & $\begin{array}{l}\text { Aschero y } \\
\text { Hocsman } \\
(2011)\end{array}$ & $\begin{array}{l}\text { Fernández } \\
1983, \\
\text { Fernández } \\
\text { Distel (2007), } \\
\text { Hoguin (2013) }\end{array}$ & $\begin{array}{l}\text { Núñez et al. } \\
\text { (2005) }\end{array}$ \\
\hline
\end{tabular}

Tabla 3: Comparación de la presencia de lascas y hojas utilizadas como formas base de instrumentos líticos durante el Holoceno temprano, medio y medio final en la Puna de Salta, Catamarca y Jujuy, y la cuenca del salar de Atacama (Chile) 
Las formas base presentan un cambio macroregional por la proliferación de tecnología de hojas en el Holoceno medio final (Tabla 3). La asociación entre artefactos lanceolados unifaciales y hojas en la Puna de Salta fue también identificada en la Puna de Jujuy con la denominada industria saladillense (Fernández 1983). Al contrario, la presencia de la tecnología de hojas es prácticamente nula en la Puna de Catamarca (Aschero y Hocsman 2011). En el caso de Chile, la presencia de esta tecnología se relaciona con el aumento de "láminas" en Tulán, también durante el Holoceno medio final (Núñez 1992; Núñez et al. 2005).

\section{Discusión}

\section{Holoceno temprano}

La evidencia del sitio Alero Cuevas permitió dar cuenta de la ocupación humana por parte de cazadores recolectores en el Holoceno temprano, con una subsistencia basada en el consumo de camélidos silvestres (guanaco y vicuña). Al respecto, la diferenciación interespecífica de camélidos a partir de osteometría permitió identificar guanacos de tamaño mayor que los actuales. Esta misma característica es común en distintos sitios del Holoceno temprano de la Puna argentina y el norte de Chile. A partir del Holoceno medio los especímenes asignables a guanaco son menores que en el Holoceno temprano, acercándose al tamaño actual de esta especie. Esta tendencia de disminución del tamaño en el tiempo se ha observado en distintas especies (Mengoni Goñalons y Yacobaccio 2006).

La comparación macroregional indica que la Puna de Salta presenta evidencias distintivas en relación con el consumo de recursos faunísticos con respecto a la tendencia general de la Puna argentina y el norte de Chile. Al respecto, la figura 2 muestra que la Puna de Salta tiene un porcentaje más alto de camélidos (por encima del $90 \%$ ) que el resto de la Puna en el Holoceno temprano. Por lo tanto, se puede sostener que el uso de los camélidos -los cuales habrían constituido recursos importantes en el desarrollo de ocupaciones recurrentes de determinados espacios- registra variabilidad macroregional durante el Holoceno temprano. Este sería el caso de Alero Cuevas en la Puna de Salta (López 2008).

La variabilidad en el uso de fauna durante el Holoceno temprano se evidencia también en las características etarias de los conjuntos. Si bien en promedio los especímenes no fusionados conforman alrededor del $40 \%$ del conjunto de la Puna argentina/Chile, la variabilidad -medida por el coeficiente de variación- es alta. En la Puna de Salta, la tendencia es similar al promedio general, con un mayor porcentaje de especímenes fusionados.

En relación con la tecnología lítica, el Holoceno temprano muestra cierta variación en la morfología de las puntas de proyectil. Sin embargo, comparativamente con el Holoceno medio, la variabilidad de clases de puntas es menor, predominando las formas triangulares apedunculadas. Esta clase de puntas se relacionaría con técnicas de caza basadas en sistemas de armas de propulsor de dardos (Aschero y Martínez 2001; Moreno 2011; Ratto 2003; Restifo 2013a). A nivel tecnológico, se registra el empleo de lascas como formas base para la confección de instrumentos, mientras que la tecnología de hojas estaría prácticamente ausente en las distintas regiones consideradas. A partir de estos datos, se plantea aquí como hipótesis, que los grupos humanos del Holoceno temprano tendieron al desarrollo de estrategias tecnológicas "minimizadoras del tiempo" o de más bajo costo (ver Bousman 
1993). La evidencia de la Puna de Salta, especialmente desde el sitio Alero Cuevas, sugiere esta misma tendencia (Restifo 2013b), aunque se debe profundizar en el análisis de las distintas variables que afectan las estrategias tecnológicas.

\section{Holoceno medio}

Durante el Holoceno medio, los camélidos aumentan en promedio su frecuencia relativa en las tierras altas del norte de Argentina y Chile. En la Puna de Salta también aumentan pero, como se señaló anteriormente, los camélidos fueron predominantes desde el Holoceno temprano con valores superiores al $90 \%$. El incremento en el consumo de estos recursos a nivel regional fue considerado un indicador de los procesos de intensificación ocurridos desde el Holoceno medio (Yacobaccio 2001). En la Puna de Salta, la evidencia arqueofaunística no es clara con respecto a una variabilidad entre el Holoceno temprano y medio. Inclusive, los especímenes no fusionados se mantienen en valores cercanos a los del Holoceno temprano. En cambio, a nivel general se evidencia un aumento de los especímenes fusionados por sobre los no fusionados, lo que sugiere un mayor consumo de animales adultos por sobre los subadultos durante el Holoceno medio, aun cuando el coeficiente de variación es muy alto. La diferenciación interespecífica de camélidos a partir de osteometría, registra una disminución en el tamaño de los especímenes de guanaco (más cercanos a estándares actuales). Sin embargo, en algunos casos como Susques, en la Puna de Jujuy, se han detectado valores similares a los de la llama, y en Chile se ha registrado una alta variabilidad en los tamaños (Cartajena 2013, Yacobaccio 2006).

Las clases de puntas muestran una variabilidad más alta que en el Holoceno temprano, con la proliferación de nuevas variantes, tales como distintas clases de lanceoladas, y la persistencia de otras con mayor profundidad cronológica. La tabla 2 presenta la aparición y proliferación de un total de 6 clases nuevas y la persistencia de otras 4 en las tierras altas del Noroeste argentino y el norte de Chile. Por su parte, en la Puna de Salta se registraron 7 nuevas variantes, que reflejan gran parte de la variabilidad macroregional. ¿Cómo explicar esta variabilidad? La aparición de nuevas clases, fundamentalmente las lanceoladas de mayor tamaño, se relacionaría en parte con la implementación de nuevas técnicas de caza y distintos sistemas de armas (Aschero y Martínez 2001, Moreno 2011, Ratto 2003, Restifo 2013 a). Aschero y Martínez (2001) propusieron un modelo de caza colectiva para estos contextos que habría demandado la participación de un mayor número de personas, relacionado también con grupos sociales más grandes. Este aumento del tamaño de los grupos sociales en contextos de circunscripción espacial asociado a una segmentación del ambiente mucho mayor durante el Holoceno medio, podría haber dado lugar al surgimiento de nuevas variantes de puntas en comparación con el Holoceno temprano. En este sentido, Muscio (2012) propone que el aumento de la tasa de innovaciones tecnológicas se relaciona con el aumento del tamaño de la población.

En términos generales, esta variabilidad también puede enmarcarse en los comienzos de un proceso de intensificación en el consumo de los camélidos. El aumento de la demanda energética habría requerido nuevas variantes, en general más eficientes para aumentar la tasa de retorno en la obtención o la caza de las presas, y también en su procesamiento. En este sentido, se debe señalar un aumento de la complejidad en la manufactura de los instrumentos, en particular de algunas clases como las puntas lanceoladas grandes, que presentan una mayor inversión de energía. Esto se relaciona con la aparición de tecnología 
de hojas o extracciones laminares en varios contextos (aunque todavía en baja frecuencia), que demandan mayores costos de manufactura y aprendizaje. Por el contrario, el proceso de manufactura de algunas clases de puntas, como las triangulares apedunculadas registradas en el Holoceno temprano, sugiere una elección oportunista de las formas base (lascas), y un menor grado de predeterminación en la obtención de la misma (ver Hoguin y Restifo 2012; Hoguin 2013). Estas características, en general, parecen dar cuenta de un cambio en las estrategias tecnológicas hacia "la maximización del rendimiento de los recursos", es decir, tecnologías más eficientes pero de mayores costos, a nivel macroregional desde el Holoceno medio (López y Restifo 2012).

\section{Holoceno medio final}

Durante el Holoceno medio final, la evidencia arqueológica de la Puna de Salta registra cambios relevantes. En la fauna se presentan variaciones notables en la diferenciación interespecífica de camélidos y en el perfil etario. En el primer caso, se registran especímenes con rangos de tamaño similares a los de la llama actual. En consecuencia, los cambios osteométricos en la Puna de Salta podrían estar reflejando la presencia de camélidos domesticados durante el Holoceno medio final (López 2013; López y Restifo 2012). Esto podría ser producto de un proceso de domesticación y/o la introducción de camélidos domesticados desde otras regiones. En este sentido, concurrentemente con los cambios osteométricos, se registra un aumento de los especímenes no fusionados. Los sitios Alero Cuevas y Abrigo Pozo Cavado reflejan una alta presencia de camélidos subadultos, a diferencia de lo registrado en el Holoceno temprano y medio (López 2013). A nivel macroregional se evidencia un aumento importante en la representación de especímenes no fusionados, pero con variabilidad entre sitios.

Estos cambios podrían interpretarse ya sea como consecuencia de la domesticación de camélidos (enfermedades producto del encierro o estrategias reproductivas para la propagación de los animales domesticados), o derivados de presiones sobre los recursos de caza (Broughton 1999; Wheeler 1998). Esto es esperable en contextos en que aumenta el tamaño de los grupos y la demanda energética (López 2008).

A escala macroregional, distintos sitios arqueológicos muestran ocupaciones a cielo abierto y en cuevas, con altas densidades de materiales, y en el caso de Chile, se suma la presencia de estructuras arquitectónicas agrupadas (Núñez 1992; Núñez et al. 2010). Los sitios Puripica 1 y Tulán 52 en la cuenca del salar de Atacama, fechados en el Holoceno medio final, presentan estas características. En Argentina, si bien para estas fechas no hay estructuras agrupadas, sitios como Río Grande en Jujuy y Ramadas Perfil Norte en Salta, reflejan la depositación de altas densidades de material arqueológico con fechados en capa en el Holoceno medio final (Fernández 1983; Muscio et al 2011). Estas características podrían estar relacionadas con mayores tamaños de grupo, circunscripción espacial relacionada con la segmentación del ambiente, y una menor movilidad residencial, aspectos que habrían aumentado la presión sobre los recursos de caza -particularmente los de más alto rendimiento- y la posibilidad de domesticar y/o introducir animales domesticados (López 2008). Las características del registro arqueológico macroregional permiten plantear hipótesis relacionadas con procesos de intensificación y domesticación de camélidos (Yacobaccio 2001). 
Las clases de puntas de proyectil registran una alta variabilidad en la escala local aunque hay morfologías compartidas en todas las regiones (e.g las lanceoladas pequeñas). Esta variabilidad también se refleja en los cambios tecnológicos. En este sentido, la presencia de tecnología de hojas o de extracciones laminares está documentada en la Puna de Salta y Jujuy, y en la cuenca del salar de Atacama, pero su presencia es escasa o nula en la Puna de Catamarca.

El aumento de la tecnología de hojas se relacionaría con una estrategia tecnológica más compleja, dados los mayores costos en la manufactura y aprendizaje para la extracción de esta forma base (Bar-Yosef y Kuhn 1999; López y Restifo 2012; Nelson 1991; Restifo 2013b). En la Puna de Salta, la presencia de hojas se asocia con artefactos lanceolados unifaciales, que en la Puna de Jujuy fueron asignados a la industria Saladillo (Fernández Distel 1978). Como hipótesis para evaluar a futuro, se propone aquí que la tecnología de hojas y estos instrumentos cumplieron un rol eficiente en el procesamiento de recursos, principalmente los camélidos, en contextos de intensificación y domesticación de los mismos. Sin embargo, no se descartan otras funciones, tanto para el procesamiento de vegetales como su uso como tecnología extractiva en algunos casos.

A partir del Holoceno medio final, las mayores presiones dependientes de la densidad poblacional en un ambiente altamente segmentado, en conjunto con procesos de circunscripción espacial, habrían llevado a un aumento de la competencia por los recursos, generando una mayor presión sobre los mismos (López 2008). Esto se desprende del modelo de tamaño óptimo de grupos, a partir del cual se plantea que estos pueden seguir creciendo aún a expensas de una pérdida de la tasa de retorno en contextos de competencia (Boone 1992; López 2008). En este marco, la intensificación en los recursos de más alto ranking (guanaco y vicuña), habría requerido nuevas tecnologías que aumentaran la eficiencia del nicho, tales como la tecnología de hojas. A su vez, la domesticación y/o introducción de camélidos domesticados podría haber sido una estrategia importante para la minimización del riesgo, a partir de la diversificación de la base de recursos (Escola 2002; López 2008; Pintar 1995).

En este contexto, la intensificación y la domesticación de los camélidos, y la diversificación en el nicho económico que esto generó, podrían ser consideradas estrategias adaptativas en el marco de mayores presiones ecológicas y sociales (López 2008; López y Restifo 2012; Restifo 2013b). Asimismo, la persistencia de los cambios tecnológicos (e.g. la tecnología de hojas), puede ser considerada una forma de aumentar la eficiencia y minimizar el riesgo (López y Restifo 2012; Restifo y Hoguin 2012).

Por otra parte, la variabilidad tanto en las puntas de proyectil como en sus formas base en la escala local podría relacionarse con estos contextos de aumento de la competencia, que promoverían la aparición de distinciones locales. Ello podría explicar las variantes de puntas en la escala local y la posible ausencia de la tecnología de hojas en la Puna de Catamarca durante el Holoceno medio final. No debe descartarse la relación de esta variabilidad regional con expresiones más marcadas de territorialidad (Aschero y Hocsman 2011), lo que puede esperarse en un contexto de aumento demográfico y competencia (Klink y Aldenderfer 2005).

Si bien en la Puna de Salta, el NISP \% no muestra una tendencia significativa en el aumento de los camélidos durante el Holoceno como sí ocurre con el promedio de toda la Puna, hay otros indicadores que refuerzan la existencia de procesos de intensificación, domesticación y diversificación (e.g. diferenciación interespecífica, perfil etario, cambio 
tecnológico). Estos procesos de cambio son más notables en el Holoceno medio final. De todas formas, en términos de variabilidad local, en la Puna de Salta se registran diferencias entre áreas. Por ejemplo, la distinción entre espacios óptimos y subóptimos para la ocupación humana generaría un aumento de la competencia y diferenciación local, tal como se observa al comparar Pastos Grandes con Pocitos (ver López 2013).

\section{Conclusión}

En síntesis, aquí se plantea que los grupos humanos que ocuparon la Puna de Salta, y la Puna en general, intensificaron el consumo de los camélidos en detrimento de los recursos de más bajo ranking. Se considera que la toma de decisión humana se inclinó por intensificar el consumo de los recursos faunísticos de más alto rendimiento, aún en contextos de mayores presiones ecológicas y sociales ocurridas a partir del Holoceno medio, y especialmente en el Holoceno medio final. Los cambios tecnológicos habrían permitido aumentar la eficiencia en el consumo de estos recursos, evitando de esta forma el ingreso en la dieta de fauna de bajo ranking. La relación entre procesos de intensificación y tecnología fue observada en distintos lugares del mundo (Babot 2006; Quintero y Wilke 1995; Winterhalder 1981; entre otros).

Por su parte, la domesticación de camélidos y/o la introducción de camélidos domesticados desde otras regiones habría permitido contar con nuevas opciones de alto ranking para el consumo, impidiendo la caída debajo de un umbral adaptativo. En consecuencia, las estrategias de diversificación en relación con el consumo de fauna se centraron en recursos de alto rendimiento (camélidos silvestres y domesticados). Esto significa que las estrategias dentro del nicho habrían llevado a aumentar la eficiencia y, al mismo tiempo, minimizar el riesgo. El cambio de nicho económico, con el pastoreo como estrategia predominante, habría consolidado la diversificación y adaptación en el uso de los camélidos durante el Holoceno tardío.

Por último, es importante señalar que la Puna de Salta, dado su carácter geográfico intermedio entre la Puna de Jujuy y la Puna de Catamarca, muestra una alta variabilidad de evidencia arqueológica, que puede ser explicada más profundamente en el marco de los procesos ocurridos macroregionalmente. En esta escala, el estudio de los procesos de intensificación, domesticación y diversificación resulta más fructífero. La continuidad de las investigaciones en la Puna de Salta seguirá aportando al análisis de esta problemática.

Agradecimientos: Al CONICET, a los editores por su invitación para participar del dossier y a los evaluadores anónimos que ayudaron a mejorar el texto.

\section{Bibliografía citada}

Aschero, C.

1975 Ensayo para una clasificación morfológica de artefactos líticos aplicada a estudios tipológicos comparativos. Informe presentado al Consejo Nacional de Investigaciones Científicas y Técnicas (CONICET).

1984 El sitio Inca cueva 4: Un asentamiento precerámico en la Quebrada de Inca Cueva (Jujuy, Argentina). Estudios Atacameños 7: 62-72.

1994 Reflexiones desde el Arcaico Tardío (6000-3000 AP). Rumitacana. Revista de Antropología 1 (1): 13-17. 
Aschero, C.A. y J.G. Martínez

2001 Técnicas de caza en Antofagasta de la Sierra, Puna Meridional Argentina. Relaciones de la Sociedad Argentina de Antropología XXVI: 215-241.

Aschero, C.A. y S. Hocsman

2011 Arqueología de las ocupaciones cazadoras-recolectoras de fnes del Holoceno medio de Antofagasta de la Sierra (Puna Meridional Argentina). Chungara 43 (volumen especial): 393-411.

Aschero, C.A., S. Hocsman y N. Ratto.

2011 Las puntas de proyectil en "mandorla" de Inca Cueva 7: Caracterización ipológica e historia de vida (Puna de Jujuy, Argentina). Estudios Atacameños 41:5-28.

Aschero, C. A. Izeta y S. Hocsman

2012 New Data on South American Camelid Bone Size Changes during Middle-Late Holocene Transition: Osteometry at Peñas Chicas 1.5 (Antofagasta de la Sierra, Argentinian Puna). International Journal of Osteoarchaeology. Published online in Wiley Online Library(wileyonlinelibrary.com) DOI: 10.1002/oa.2235

Babot, $\mathrm{P}$.

2006 El papel de la molienda en la transición hacia la producción pastoril: un análisis desde la Puna meridional Argentina. Estudios Atacameños 32: 75-91.

Bar-Yosef, O. y S. Kuhn

1999 The big deal about blades: Laminar technology and human evolution. American Anthropologist 101:322-328

Boëda, E.

1997 Technogenèse des systèmes de production lithique au Paléolithique inférieur et moyen en Europe occidentale et au Proche-Orient. Habilitation à diriger des recherches. Université Paris X, Nanterre.

Boone, J.

1992 Competition, conflict and development of social hierarchies. Evolutionary Ecology and Human Behavior (Ed. por E. Smith y B. Winterhalder), pp. 301-337. Hawthorne, N. Y. Aldine de Gruyter.

Bousman, B.

1993 Hunter gatherer adaptations, economic risk and tool design. Lithic Technology 18: 59- 86.

Broughton, J.

1999 Resource depression and Intensification During the Late Holocene, San Francisco Bay. University of California Press, Berkeley, Los Angeles, London.

Cartajena, I.

2013 Faunal assemblages from the Middle Holocene: Environmental and cultural variability in the western slope of the Puna de Atacama. Quaternary international 307: 31-37 
De Souza, P.

2004 Cazadores recolectores del Arcaico Temprano y Medio en la Cuenca del río Loa: sitios, conjuntos líticos y sistemas de asentamiento. Estudios Atacameños 27: 7-44.

Escola

2002 Caza y Pastoralismo: un Reaseguro para la Subsistencia. Relaciones de la Sociedad Argentina de Antropología XXVII: 232- 245.

Fernández, J.

1983 Río Grande. Exploración de un centro precerámico en las altas montañas de Jujuy, Argentina. Ampurias 45/46: 54-83.

Fernández Distel, A.

1978 Nuevos hallazgos precerámicos en la región de Salinas Grandes, Puna de Jujuy, Argentina. Revista del Instituto de Antropología tomo VI: 15- 62, Universidad de Córdoba.

Fitzhugh, B

2001 Risk and invention in human technological evolution. Journal of Anthropological archaeology 20: 125-167.

Hocsman, S.

2006 Producción lítica, variabilidad y cambio en Antofagasta de la Sierra ca. 5500 -1500 AP. Tesis de doctoral. Facultad de Ciencias naturales y Museo, La Plata. Inédita.

Hoguin, R.

2013 Evolución y cambios técnicos en sociedades cazadoras recolectoras de la Puna Seca de los Andes Centro-Sur Tecnología lítica en la localidad de Susques durante el Holoceno temprano y medio. Tesis de doctorado. Universidad de Buenos Aires. Inédita.

Hoguin R. y F. Restifo

2012 Cultural transmission patterns in projectile points manufacture: Implications for the early settlement of the Argentinean Puna. Current Research in the Pleistocene. Special edition: 69-74.

Hoguin R. y H. Yacobaccio

2012 Análisis lítico de ocupaciones del Holoceno Medio de Hornillos 2 (Jujuy, Argentina): discutiendo la tecnología y distribución de las puntas de proyectil "San Martín". Chungara 44 (1): 85-99.

Johnson, A., A. Gil, G. Neme y J. Freeman

2009 Maíces e intensificación: Explorando el uso de los marcos de referencia. En Arqueología y evolución: Teoría, Métodos y casos de estudio, editado por Gabriel López y Marcelo Cardillo, Editorial sb. Buenos Aires, Argentina, pp 23-47.

Klink, C.J., Aldenderfer, M.S.

2005 A projectile point chronology for the South-Central Andean Highlands. Advances in Titicaca Basin Archaeology, vol. 1 (Ed. por Stanish, C., Cohen, A.B., Aldenderfer, M.S.), pp. 25-54. Cotsen Institute of Archaeology, University of California, Los Angeles. 
Lavallée. D., Julien, M., Karlin, C., García L., Pozzi-scot, D. y M. Fontugne

1997 Entre desierto y quebrada. Primeros resultados de las excavaciones realizadas en el abrigo Tomayoc (Puna de Jujuy, Argentina). En Bulletin d'Institut Francais d'Etudes Andines, Tomo 26, Número 2, Ministerio de Relaciones Exteriores de Francia, pp. 141-175, Lima, Perú.

López, G.

2008 Arqueología de cazadores y pastores en tierras altas. Ocupaciones humanas a lo largo del Holoceno en Pastos Grandes, Puna de Salta, Argentina. BAR international series 1854, Oxford. Inglaterra. 2013 Ocupaciones humanas y cambio a lo largo del Holoceno en abrigos rocosos de la Puna de Salta, Argentina: Una perspectiva regional. Chungara 45 (3): 411-426.

López, G. y F. Restifo.

2012 The Middle Holocene domestication and intensification of camelids in north Argentina, tracked by zooarchaeology and lithics. Antiquity 86 (334): 1041-1054.

López, G., F. Coloca y J. Orsi

2013 Human Occupations during the Middle Holocene and Beginning of the Late Holocene the Pocitos Basin, Puna of Salta, Argentina: New Research and Regional Comparison. Quaternary International 307: 50-57.

Martínez, J.

2003 Ocupaciones humanas tempranas y tecnología de caza en Antofagasta de la Sierra (10000-7000 $A P)$. Tesis Doctoral. Facultad de Ciencias Naturales e Instituto Miguel Lillo. Universidad Nacional de Tucumán.

Mengoni Goñalons, G. y H. Yacobaccio

2006 The domestication of South American camelids. A View from the South-Central Andes. En Documenting Domestication, New Genetics and Archaeological Paradigms, editado por M. Zeder, D. Bradley, E. Emshwiller y B Smith, University of California Press, Berkeley, pp. 228-243.

Mondini, M., Martínez, J., Pintar, E. y M. Reigadas

2013 Middle Holocene foraging, mobility and landscape use in the southern Argentinean Puna: Hunter gatherers from Antofagasta de la Sierra, Catamarca, Argentina. Quaternary International 307: 66-73

Morales, M.

2011 Arqueología ambiental del Holoceno temprano y medio en la Puna Seca Argentina. Modelos paleoambientales multiescalas y sus implicancias para la arqueología de cazadores recolectores. BAR International Series, Oxford.

Moreno, E.

2011 Tecnología de caza en Antofalla, Departamento de Antofagasta de la Sierra, Catamarca. Revista del Museo de Antropología 4: 17-32.

Muscio, $\mathrm{H}$.

2012 Modelling demographic dynamics and cultural evolution: The case of the early and mid Holocene archaeology in the highlands of South America. Quaternary International 256: 19- 26. 
Muscio, H. y G. López

2011 Particularidades de la arqueología de la Puna Argentina, invisibilización de su variabilidad y estado actual del conocimiento: una introducción. En Arqueología de la Puna Argentina: perspectivas actuales en el estudio de la diversidad y el cambio cultural. South American Archaeology Series 16, editado por Gabriel López y Hernán Muscio, BAR S2296, Oxford. pp. 1-18.

Muscio, H., Restifo, F., Carballo, G., Seguí, S. y Vardé, M.

2011 Ocupaciones humanas de finales del Holoceno medio en San Antonio de los Cobres. Taller de Arqueología del Noroeste Argentino. Universidad Nacional de Córdoba, Provincia de Córdoba, Argentina.

Nelson, M.

1991 The study of technological organization. Archaeologic Method and Theory 3: 57-100.

Neme, G.

2002 Arqueología del alto valle del río Atuel: modelos, problemas y perspectivas en el estudio de las regiones de altura del sur de Mendoza. Entre montañas y desiertos: arqueología del sur de Mendoza, (Ed. por A. Gil y G. Neme), pp. 65-83. Publicaciones de la Sociedad Argentina de Antropología.

Núñez, L.

1992 Ocupación arcaica en la Puna de Atacama: secuencia, movilidad y cambio. Prehistoria Sudamericana: Nuevas Perspectivas (Ed. por B. Meggers), pp. 283-307. Taraxacum, Washington.

Núñez, L, M. Grosjean e I. Cartajena

2005 Ocupaciones humanas y Paleoambientes en la Puna de Atacama. Instituto de investigaciones arqueológicas y museo. Universidad Católica del Norte-Taraxacum, San Pedro de Atacama, Chile.

2010 Sequential analysis of human occupation patterns and resource use in the Atacama dessert. Chungara 42 (2): 363-391.

Olivera, D.

2012 El Formativo en los Andes del sur: la incorporación de la opción productiva. En Interculturalidad y ciencias: Experiencias desde América latina, editado por M. Haro, A. Rocchietti, M. Runcio, O. Hernández de Lara y V. Fernández, pp. 15 - 49, Editorial Centro de Investigaciones precolombinas, Buenos Aires.

Patané Aráoz, J.

2013 Prospecciones arqueológicas en Salinas Grandes (Departamento La Poma, Provincia de Salta) y reporte de una punta "cola de pescado". Relaciones de la Sociedad Argentina de Antropología XXXVIII (1): 247-255.

Pintar, E.

1995 Los conjuntos líticos de los cazadores holocénicos en la Puna Salada. Arqueología 5: 9-23. 2014 Continuidades e hiatos ocupacionales durante el Holoceno medio en el borde oriental de la Puna Salada, Antofagasta de la Sierra, Argentina. Chungara 46 (1): 51-71. 
Quintero, L. \& P.Wilke.

1995 Evolution and economic significance of Naviform core and blade technology in the southern Levant. Pal'eorient 21: 17-33.

Ratto, N.

2003 Estrategias de caza y propiedades del registro arqueológico en la Puna de Chaschuil (Departamento de Tinogasta, Catamarca, Argentina). Tesis doctoral. Facultad de Filosofía y Letras. Universidad de Buenos Aires, Argentina.

Restifo, F.

2013a Tecnología de caza durante el Holoceno temprano y medio en la Puna de la Provincia de Salta (República Argentina): Patrones de variación y procesos de cam-bio. Comechingonia 17: 59-84.

2013b Tecnología lítica en la Puna de la Provincia de Salta a lo largo del Holoceno temprano y medio: Patrones de variación y procesos de cambio. Tesis de doctorado. Facultad de Filosofía y Letras, UBA. Inédita.

Restifo, F. y R. Hoguin

2012 Risk and technological decision-making during the early to mid-Holocene tran $\neg$ sition: A comparative perspective in the Argentine Puna. Quaternary International 256: 35-44.

Wheeler, J.C.

1998 Evolution and origin of the domesticated camelids. Alpaca Registry Journal 3: 1-16.

Winterhalder, B

1981 Optimal foraging strategies and hunter-gatherer research in anthropology: Theory and models. Hunter- gatherer foraging strategies. Ethnographic and archaeological analysis (Ed. Por B. Winterhalder y E. Smith), pp 13-35. University of Chicago.

Winterhalder, B., F. Lu y B. Tucker

1999 Risk-Sensitive Adaptative Tactics: Models and Evidence from Subsistence Studies in Biology and Anthropology. Journal of Archaeological Research 7 (4): 301-348.

Yacobaccio, $\mathrm{H}$.

2001 Cazadores complejos y domesticación de camélidos. El Uso de los Camélidos a través del Tiempo. (Ed. por G. Mengoni Goñalons, D. E. Olivera y H.D. Yacobaccio), pp. 261-281. Ediciones del Tridente, Buenos Aires.

2006 Intensificación económica y complejidad social encazadores-recolectores surandinos. Boletín de arqueología PUCP 10: 305-320.

2013 Towards a Human Ecology for the Middle Holocene in the Southern Puna. Quaternary international 307: 24-30

Yacobaccio H.D., y V. Vilá.

2002 Condiciones mecanismos y consecuencias de la domesticación de camélidos. Estudios Sociales del NOA 3: 4-27.

Yacobaccio, H., Madero, C.; Malmierca, M. Y M. Reigadas.

1997-1998 Caza, domesticación y pastoreo de camélidos en la Puna Argentina. Relaciones de la Sociedad Argentina de Antropología XXII- XXIII: 389-428 